Received 00th January 20xx, Accepted 00th January 20xx

DOI: $10.1039 / x 0 x x 00000 x$

www.rsc.org/

\title{
Improving the electrocatalytic performance of sustainable Co/Carbon materials for oxygen evolution reaction by ultrasound and microwave assisted synthesis
}

Alessio Zuliani, $\ddagger^{\text {a }}$ Manuel Cano, $\ddagger^{\text {b }}$ Federica Calsolaro, ${ }^{c}$ Alain R. Puente Santiago, d Juan J. Giner-Casares, ${ }^{b}$ Enrique Rodríguez-Castellón, ${ }^{e}$ Gloria Berlier, ${ }^{f}$ Giancarlo Cravotto, ${ }^{c}$ Katia Martina ${ }^{c}$ and Rafael Luque ${ }^{a, g *}$

\begin{abstract}
The design of sustainable procedures for the preparation of Cobalt/Carbon-based materials as anode for hydrogen fuel production through the electrocatalytic water splitting has attracted much interest in the last years. Herein, a novel environmentally friendly approach for the development of stable and active catalysts for the oxygen evolution reaction $(\mathrm{OER})$ is reported. In details, the methodology aimed at developing a sequence of composites having a low-cobalt loading $(<4 \%$ wt) using polyphenols extracted from green tea as metal stabilizers and activated carbon derived from pinecones as metal-supporting as well as co-active material. The approach exploited ultrasound (US), microwave (MW) and combined US/MW-assisted techniques with the purpose of enhancing the final electrocatalytic activity of these new composites, replacing the conventional high-temperature approaches. The results indicated that the so-produced electrocatalytic materials followed the order of activity US>MW/US>MW>conventional heating, with the best sample requiring an overpotential of $365 \mathrm{mV}$ to deliver the current density of $10 \mathrm{~mA} \cdot \mathrm{cm}^{-2}$ and a Tafel slope of $58 \mathrm{mV} \mathrm{dec}{ }^{-1}$.
\end{abstract}

\section{Introduction}

The ambitious challenge of developing cheap and efficient fuel cells, metal-air batteries as well as systems for energy conversion or storage necessarily passes through the design of low-cost and highly active electrocatalyst materials. ${ }^{1-6}$ For example, considering the case of water-splitting, i.e. "the electrolysis of water to hydrogen and oxygen", 7 the evolution of hydrogen (HER) occurs at the cathode, while the oxygen evolution reaction (OER) takes place at the anode. ${ }^{8}$ The design of cheap and stable active electrocatalyst materials for the OER is particularly attractive due to the elevated overpotential needed for the oxidation of water. ${ }^{9}, 10$ In fact, while the HER is a two-electron transfer reaction, the OER is a four-electron oxidation, having a higher kinetic barrier. ${ }^{11}$

a Departamento de Quımica Organica, Universidad de Cordoba, Edificio Marie-Curie (C-3), Ctra Nnal IV-A, Km 396, E14014, Cordoba, Spain. E-mail: rafael.luque@uco.es ${ }^{b}$ Departamento de Química Física y Termodinámica Aplicada, Instituto Universitario de Nanoquímica (IUNAN), Campus de Rabanales, Edificio Marie Curie (C-3), Ctra Nnal IV-A, Km 396, E14014, Córdoba, Spain.

c Dipartimento di Scienza e Tecnologia del Farmaco, University of Turin, Via Pietro Giuria 9, 10125 Turin, Italy.

${ }^{d}$ Department of Chemistry and Biochemistry, University of Texas at El Paso, $500 \mathrm{~W}$. University Avenue, EI Paso, Texas 79968, USA

e Departamento de Química Inorgánica, Universidad de Málaga, E-29071, Málaga Spain.

${ }^{f}$ Department of Chemistry, University of Turin, via Quarello 15, I-10135 Turin, Italy. g Peoples Friendship University of Russia (RUDN University), 6 Miklukho-Maklaya str. Moscow, 117198, Russia

Electronic Supplementary Information (ESI) available: Picture of the MW/US apparatus, EDX mapping, XRD patterns, $\mathrm{N}_{2}$ physisorption isotherms, $\mathrm{C}$ 1s and $\mathrm{N}$ 1s core level spectra. See DOI: 10.1039/x0xx00000x

$\ddagger$ These authors contributed equally to this work
Some precious metals, such as $\mathrm{Pt}, \mathrm{Ir}$ and $\mathrm{Ru}$, and their oxides, have been reported between the most active electrocatalysts for OER. ${ }^{12-14}$ However, the high costs and, in some cases, the low stability, make their commercial application impractical. ${ }^{15}$

The substitution of noble metals has focused on relatively inexpensive and Earth's crust abundant metals such as $\mathrm{Mn}, \mathrm{Fe}$, $\mathrm{Cu}, \mathrm{Ni}$ and Co. ${ }^{16,17}$ Cobalt, which market has dramatically slump in $2019,{ }^{18}$ making the metal much more affordable, have been studied as efficient OER catalysts since 1980 s. $^{19}$ Within that time, the literature has reported numerous successful novel Co-based OER catalysts, which can be divided into five different categories: nitrogen-doped ( $\mathrm{N}$-doped) carbon composites, oxides/hydroxides, chalcogenides, phosphides, and phosphates. ${ }^{20}$ Basing on the principles of green chemistry, cobalt-N-doped carbon composites have particularly emerged since they can be produced from biowaste-derived carbon, resulting in materials having a sensibly low carbon footprint. ${ }^{21}$ For example, some commonly employed carbon bio-sources include inexpensive and abundant algae, chitin or eggshells. ${ }^{22-24}$ In addition, the porous nature of some of these biowaste can enhance the electrocatalytic properties of the final electrocatalysts. ${ }^{22,25}$ It must be also highlighted that in cobalt$\mathrm{N}$-doped carbon composites, a synergism effect could be observed as, a part from the metal active sites, the carbon itself can slightly catalyse the OER. ${ }^{26-32}$

However, despite the ideal aim of creating sustainable catalysts, the preparation of $\mathrm{N}$-doped carbon composites normally entails some environmental and ethical drawbacks. These important limits are attributable to the massive use of cobalt or to the low efficiency of the synthetic methodologies. In fact, conventional technologies (i.e. conventional heating) are still the major 
techniques used for the preparation of the electrocatalysts with remarkably energy-consumption disadvantages. In addition, and more importantly, a high content of cobalt is normally employed, ideally forcing the already intense and alarming mining of Co. Indeed, two-third of Co mines are placed in the Democratic Republic of the Congo (DRC), where the population is suffering of toxic pollution (due to artisanal mining) and child exploitations. ${ }^{33-35}$ As a result, if on a side Co remains economically convenient and catalytically efficient, its utilization should be diminished as much as possible.

The purpose of this work is to demonstrate the possibility to prepare active Co-based material for the OER reaction, having a low metal content, employing low toxicity and biomass derived reagent through environmentally friendly and energetically efficient synthetic techniques, such as microwave (MW)-, ultrasound (US)-assisted or both in combination (MW/US). MWand US-heating are based on the interaction of matter with electromagnetic and ultrasound irradiations, respectively. ${ }^{36,37}$ Remarkably, US and MW assisted techniques are increasingly widely used in synthesis and catalysis. ${ }^{38}$ Some of the most important advantages of the latter heating approaches are: (i) direct transfer of energy to the reactants instead of transferring heat, (ii) independence of heat convection, (iii) rapid heating rates, and (iv) the possibility of obtaining volumetric, local and material-selective heating. ${ }^{39-44}$ Carbon-based materials are, in general, very good microwave and ultrasound absorbers. According to the literature, a synthetic strategy that takes in consideration all these aspects simultaneously has not been reported yet.

A sequence of electrocatalysts based on Co has been prepared using carbon derived from pinecones and employing US, MW and combined MW/US techniques. A low metal loading of $\sim 4 \%_{w t}$ was selected, alternatively to the $25-50 \%_{w t}$ metal loading normally reported in the literature for this type of materials. ${ }^{45-}$ 48 Carbon derived from pinecones has been selected due to the large availability, interesting composition in terms of cellulose and lignin content, and low cost. In addition, it has been demonstrated that activated carbon from pinecones exhibit enhanced properties for the adsorption of metals at basic $\mathrm{pH}$ values. ${ }^{49-60}$ The $\mathrm{N}$-doping of carbon has been performed using a low-toxicity nitrogen source, i.e. urea. ${ }^{61}$ Polyphenols extracted from green tea were used as stabilizer and ligand of cobalt, having similar phenolic functional groups of Co-ligands reported in the literature.62-65 With all of these considerations, a sequence of seven different samples was prepared and exhaustively characterized by powder X-ray diffraction (XRD), $\mathrm{N}_{2}$ physisorption (Langmuir model), scanning electron microscopy (SEM) plus energy-dispersive X-ray spectroscopy (SEM-EDX), inductively coupled plasma mass spectrometry (ICP-MS) and X-ray photoelectronic spectroscopy (XPS). All the materials were tested as electrocatalyst for OER reaction, studying the influence of the use of carbon derived from pinecones (using commercially available activated carbon as counterpart), the doping with nitrogen, the stabilization with polyphenols and the influence of the different synthetic procedures (i.e. conventional heating vs MW and US procedures) on the final electrocatalytic activities. The most active materials were also tested operating at 60 and $80^{\circ} \mathrm{C}$. According to the literature, the best sample was found to be classifiable as an "excellent" electrocatalyst for the OER reaction. 66

\section{Experimental}

\section{Materials}

All the reagents employed in the synthesis and in the reactions were of analytical grade purity and were used without any further purification. Absolute ethanol $\left(\mathrm{CH}_{3} \mathrm{CH}_{2} \mathrm{OH}\right)$, acetone $\left(\mathrm{CH}_{3} \mathrm{COCH}_{3}\right)$, isopropanol $\left(\left(\mathrm{CH}_{3}\right)_{2} \mathrm{CH}_{2} \mathrm{OH}\right)$ acetonitrile $\left(\mathrm{CH}_{3} \mathrm{CN}\right)$, potassium hydroxide $(\mathrm{KOH})$, cobalt $(\mathrm{II})$ acetate $\left(\mathrm{Co}(\mathrm{OAC})_{2}\right)$, urea $\left(\mathrm{CH}_{4} \mathrm{~N}_{2} \mathrm{O}\right)$ and Nafion 117 solution ( $\sim$ \%) were purchased from Sigma-Aldrich Inc. (St. Louis, MO, USA). Green Malaysian tea was bought in a local market in Turin (Italy). Pinecones were collected in "Parco Valentino" nearby the University of Turin (Italy). Commercial activated carbon Charcoal Norit CA1, from wood, was purchased from Sigma-Aldrich Inc. (St. Louis, MO, USA).

\section{Preparation of Cobalt/pinecones catalyst}

A sequence of catalysts containing $\sim 4 \%_{\text {wt }}$ cobalt supported over activated carbon (AC) was prepared. The sequence includes samples prepared aiming at investigating the difference between commercially available carbon and carbon derived from pinecones; the effect of the doping with nitrogen; the influence of the synthetic procedure for the adsorption of the metal (conventional vs MW vs US vs combined MW/US heating) and the impact of the utilization of polyphenols extracted from green tea as metal stabilizers. The catalysts were prepared according to a schematic diagram reported in Fig.1.

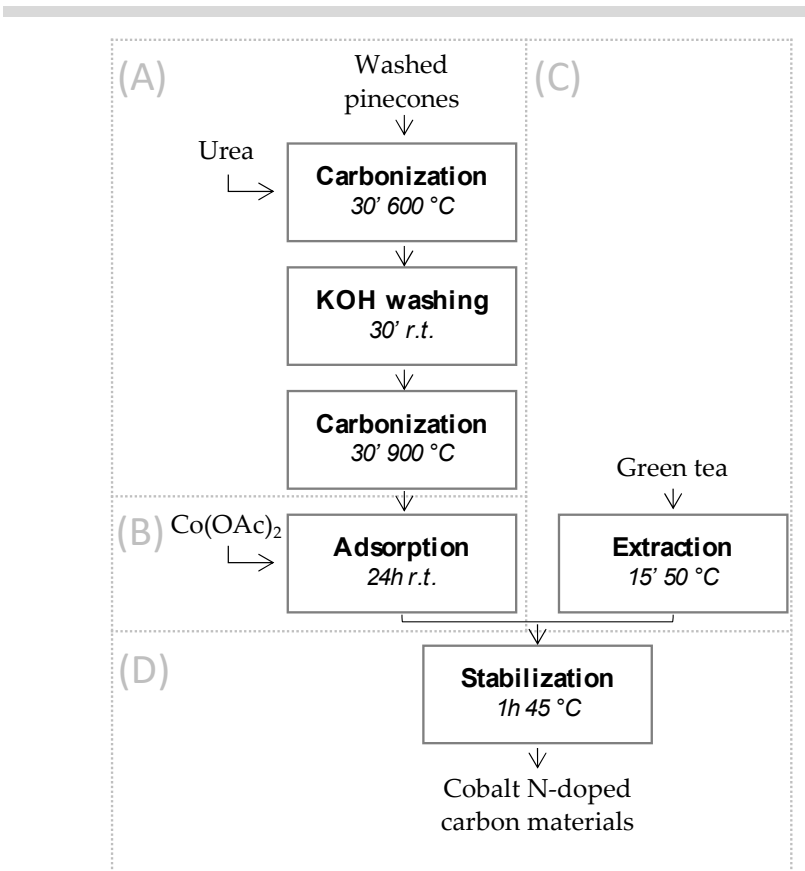

Fig. 1 Schematic diagram for the preparation of the Cobalt N-doped carbon materials. 
Preparation of carbon derived from pinecones (Fig.1 (A))

Prior to the utilization, pinecones were washed in a US bath for $30^{\prime}$ with a 1:1:1 mixture of water, acetone and acetonitrile, and sequentially dried in a $100{ }^{\circ} \mathrm{C}$ oven, in order to remove resins and organic traces. Washed pinecones were carbonized at 600 ${ }^{\circ} \mathrm{C}\left(30^{\prime}\right.$ at $\left.1500 \mathrm{~W}\right)$ in an Ethos microwave (Milestones Srl, Bergamo, Italy) equipped with an infrared sensor combined with an in-situ temperature sensor. Where necessary, before carbonization, pinecones were smashed together with urea using a blender (in order to obtain $10 \%_{\mathrm{wt}}$ of nitrogen in the final product). This step provided the nitrogen-doping of the final product. Sequentially, the carbonaceous materials were washed with an aqueous solution of $\mathrm{KOH}(\mathrm{KOH}$ :carbon $=2: 1)$ in a US bath, and directly filtered, avoiding the evaporation of water, a typical step in $\mathrm{KOH}$ activation trough impregnation. ${ }^{67}$ The milder $\mathrm{KOH}$ activation procedure allowed to completely clean the surface from remaining impurities without totally destroying the peculiar structure of pinecones. The filtrated pinecones carbon was sequentially washed several times with distilled water in an US bath. Finally, the carbon was filtered again and carbonized at $900{ }^{\circ} \mathrm{C}\left(30^{\prime}\right.$ at $\left.1500 \mathrm{~W}\right)$ in an Ethos microwave.

\section{Adsorption of Co on pinecones carbon (Fig.1 (B))}

A metal/carbon mixture was prepared by mixing $300 \mathrm{mg}$ of pinecones carbon (or commercially available activated carbon) and $3 \mathrm{~mL}$ of an ethanol solution $81 \mathrm{mmol}$ of $\mathrm{Co}(\mathrm{OAc})_{2}(43 \mathrm{mg})$. The mixture was left $24 \mathrm{~h}$ under stirring at room temperature, in order to let the metal ions adsorb on the carbon. ${ }^{57}$

\section{Preparation of polyphenol solution (Fig.1 (C))}

Parallelly, a solution of polyphenols was prepared by modifying a reported procedure. ${ }^{68}$ More in details, $6 \mathrm{~g}$ of green Malaysian tea were mixed with $150 \mathrm{~mL}$ of ethanol and sequentially irradiated with combined MW/US at $50^{\circ} \mathrm{C}$ for $15^{\prime}$ (100 W MW + $40 \mathrm{~W}$ US). The combined system MW/US was designed by inserting a sonic horn made of pirex inside a RotoShynth (Milestone Srl, Bergamo, Italy) microwave chamber (please see Fig. S1 in the ESI for a picture of the equipment).

\section{Preparation of Cobalt N-doped carbon materials (Fig.1 (D))}

$9 \mathrm{~mL}$ of polyphenol solution (or ethanol, for samples not containing polyphenols) were added to the mixture of metal/carbon. The resulting solution was heated at $45^{\circ} \mathrm{C}$ for 1 $\mathrm{h}$ in an oil bath or in a microwave-oven or in a US bath or in a combined MW/US apparatus. The resulting powders were filtered, washed several times with ethanol and dried at $80^{\circ} \mathrm{C}$ for $24 \mathrm{~h}$ prior to determine the final weight. Table S1 summarises of the amount (in $\mathrm{mg}$ ) of final product obtained with the different synthetic procedures.

As reported in Table 1, the samples were denoted using the following abbreviations: "CC" stands for Commercial Charcoal, "PC" for pinecones Charcoal, " $p p$ " for polyphenols and " $C$ ", " $M$ ", " $U$ " and "MU" respectively stand for "conventional-heating", "microwave-assisted", "ultrasound-assisted" and "combined microwave-ultrasound assisted" addition of polyphenols.

Table 1 List and description of the different electrocatalysts.

\begin{tabular}{cccc}
\hline Sample & Type of carbon & N-Doping & Polyphenols \\
\hline Co/CC & Commercial Charcoal & NO & NO \\
Co/PC & Pinecones Charcoal & NO & NO \\
Co/N-PC & Pinecones Charcoal & YES & NO \\
Co/N-PC-pp-C & Pinecones Charcoal & YES & YES \\
Co/N-PC-pp-M & Pinecones Charcoal & YES & YES \\
Co/N-PC-pp-U & Pinecones Charcoal & YES & YES \\
Co/N-PC-pp-MU & Pinecones Charcoal & YES & YES \\
\hline
\end{tabular}

\section{Materials characterization}

Thermogravimetric analyses (TGA) were carried out with a Mettler Toledo TGA/SDTA 851 analyser operating with alumina crucibles. The samples were heated from $25^{\circ} \mathrm{C}$ up to $900{ }^{\circ} \mathrm{C}$ at $5{ }^{\circ} \mathrm{C} \cdot \mathrm{min}^{-1}$ in nitrogen atmosphere $\left(50 \mathrm{~mL} \cdot \mathrm{min}^{-1}\right)$. Prior to analysis, the materials were conditioned at $25^{\circ} \mathrm{C}$ under nitrogen flux $\left(50 \mathrm{~mL} \cdot \mathrm{min}^{-1}\right)$ for 20 minutes. XRD patterns were recorded using a Bruker D8 DISCOVER A25 diffractometer (PanAnalytic/Philips, Lelyweg, Almelo, The Netherlands) using CuK $\alpha(\lambda=1.5418 \AA)$ radiation. Wide angle scanning patterns were collected over a $2 \theta$ range from $10^{\circ}$ to $80^{\circ}$ with a step size of $0.018^{\circ}$ and counting time of $5^{\prime \prime}$ per step. Inductively coupled plasma mass spectrometry (ICP-MS) analysis were carried out at the Research Support Service (SCAI) by digesting the samples in a solution $\mathrm{HNO}_{3}: \mathrm{HCl}=3: 1$. SEM images were recorded in a JEOL JSM-6300 scanning microscope (JEOL Ltd., Peabody, MA, USA) equipped with Energy-dispersive $X$-ray spectroscopy (SEM-EDX) at $15 \mathrm{kV}$ at the Research Support Service Centre (SCAI) from the University of Cordoba. Specific surface area (SSA), micro- and mesopore volume were calculated by gasvolumetric analysis measuring $\mathrm{N}_{2}$ adsorption-desorption isotherms at liquid nitrogen temperature using an ASAP 2020 physisorption analyser (Micromeritics). The SSA was calculated by the Langmuir method. Mesopore volume was determined by means of the Barrett-Joyner-Helenda (BJH) method, on the adsorption branch of nitrogen isotherms. Micropore volume was calculated by t-plot method. Before the measurement, the samples were outgassed at $100{ }^{\circ} \mathrm{C}$ overnight. ICP-MS analysis was performed after microwave-assisted acidic digestion of the samples and using a Perkin Elmer NexionX Spectrometer to measure the total amount of cobalt (\%wt) contained. XPS studies were performed on a Physical Electronics spectrometer (PHI Versa Probe II Scanning XPS Microprobe) with monochromatic

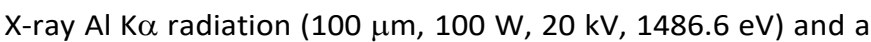
dual-beam charge neutralizer. The spectrometer was calibrated with $\mathrm{Au} 4 f_{7 / 2}, \mathrm{Ag} 3 d_{5 / 2}$ and $\mathrm{Cu} 2 p_{3 / 2}$ photoelectron lines at 84.0, 368.2 and $932.7 \mathrm{eV}$, respectively. The $A u 4 f_{7 / 2}$ line was recorded with $0.73 \mathrm{eV}$ FWHM at a binding energy (BE) of $84.0 \mathrm{eV}$, under a constant pass energy mode at $23.5 \mathrm{eV}$ condition. XPS spectra were analyzed using $\mathrm{PHI}$ SmartSoft software and processed using MultiPak 9.3 package. The binding energy values were referenced to adventitious C $1 s$ signal at $284.8 \mathrm{eV}$. Recorded spectra were fitted using Gauss-Lorentz curves. Atomic 
concentration percentages of the constituent elements of the surfaces were determined considering the corresponding area sensitivity factor for the different measured spectral regions.

\section{Preparation of the electrocatalyst materials}

Each sample (Table 1 ) was firstly dispersed $\left(5 \mathrm{mg} / \mathrm{mL}, 15^{\prime}\right.$ in an US bath) in a mixture made of $15 \mathrm{~mL} 30 \%$ vol isopropanol in water and $5 \mathrm{~mL}$ of a Nafion 117 solution ( $5 \%$, Sigma-Aldrich). The 2D working electrodes were prepared by drop-casting the different solutions over glassy carbon (GC) discs of $5 \mathrm{~mm}$ diameters (Pine Instruments Company). Before each usage, the GC electrodes were washed and cleaned. Specifically, the discs were firstly sonicated for $15^{\prime}$ in pure isopropanol in order to remove any residual Nafion. Sequentially, the electrodes were polished using two distinct alumina $\left(\mathrm{Al}_{2} \mathrm{O}_{3}\right)$ powders with different particle size $(0.2$ and $0.05 \mu \mathrm{m})$, which were previously mixed with water on the polishing pad, making a paste. After polishing, the electrodes were sonicated again at least three times (15' each one) in ultrapure water. Finally, the discs were electrochemically cleaned by performing 100 cyclic voltammetric (CV) scans into an aqueous electrolyte composed of a nitrogen-saturated $0.5 \mathrm{M} \mathrm{H}_{2} \mathrm{SO}_{4}$ plus $0.5 \mathrm{M} \mathrm{NaCl}$, at scan rate of $50 \mathrm{mV} \mathrm{s}^{-1}$.

$\mathrm{RuO}_{2}$ NPs were used as reference electrocatalyst material and were synthesized according to the precipitation method reported in the literature. ${ }^{69}$

\section{Electrochemical measurements}

Linear-sweep voltammetric (LSV) measurements were recorded using a three-electrode electrochemical cell connected to a potentiostat/galvanostat tool (AUTOLAB PGSTAT30). Ag/AgCl and $P t$ foils were used as reference and counter electrodes. The experiments were performed in an alkaline aqueous solution of $\mathrm{KOH} 0.5 \mathrm{M}$. Electrochemical measurements were recorded operating in the potential range $0.00-0.90 \mathrm{~V} v \mathrm{Ag} / \mathrm{AgCl}$, using a scan rate of $2 \mathrm{mV} \mathrm{s}^{-1}$ and $1600 \mathrm{rpm}$ of rotation rate. Current densities were obtained considering the geometric surface area, whilst all potentials were referenced to $\mathrm{RHE}$ according to the Nernst equation. ${ }^{70,71}$

The number of active sites were determined according to Stevens et al. 72, 73 More in details, a sequence of cyclic voltammetries (CVs) measurements were performed in a narrow potential window of $-0.717 \vee$ to $-0.817 \vee v s$ RHE (i.e. where no faradaic reactions occurred) at different scan rates (12-48 $\mathrm{mV} \mathrm{s}^{-1}$ at an interval of $\left.4 \mathrm{mV} \mathrm{s}^{-1}\right)$. Sequentially, the slope of the lines of the graph scan rate $v s J$ anodic-J cathodic (at $-0.767 \mathrm{~V}$ vs RHE) was used to determine the number of active sites as well as the electrochemical surface area.

\section{Results and discussion}

\section{Synthesis of Co-polyphenols/Carbon}

The synthetic procedure for the preparation of the samples involved a sequence of steps aimed to maximise the electrocatalytic activity of the final electrocatalyst materials for the OER, as summarized in Fig. 2.

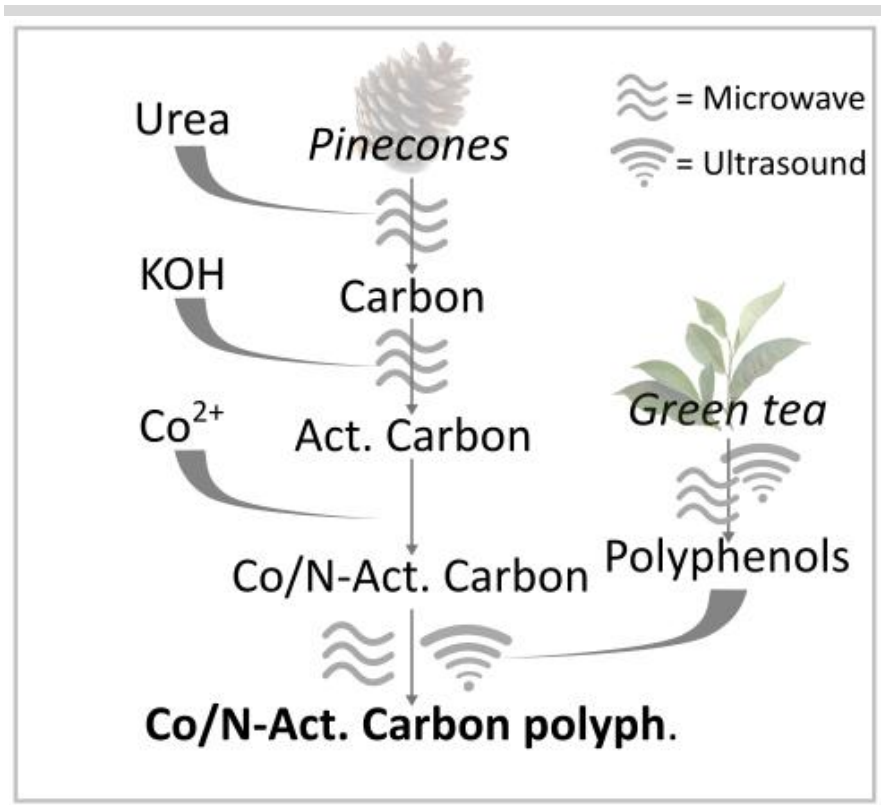

Fig. 2 Schematic diagram for the preparation of the Cobalt $\mathrm{N}$-doped carbon materials.

In the first step, the washed pinecones were carbonized in order to enhance the metal adsorption properties. ${ }^{60}$ As illustrated in TGA analysis in Fig.3, around $70 \%$ of the total weight was lost during this procedure. Just like most of the thermal degradation of wood materials, also the thermal degradation of pinecone biomass occurred in three phases: (i) moisture evaporation at $30-150{ }^{\circ} \mathrm{C}$, (ii) hemicelluloses and cellulose decomposition at 200-350 ${ }^{\circ} \mathrm{C}$, and (iii) lignin decomposition at $160-700{ }^{\circ} \mathrm{C}$. Remarkably, the larger loss of weight was observed in the temperature range of $200-375{ }^{\circ} \mathrm{C}$, corresponding to hemicellulose and cellulose decomposition.

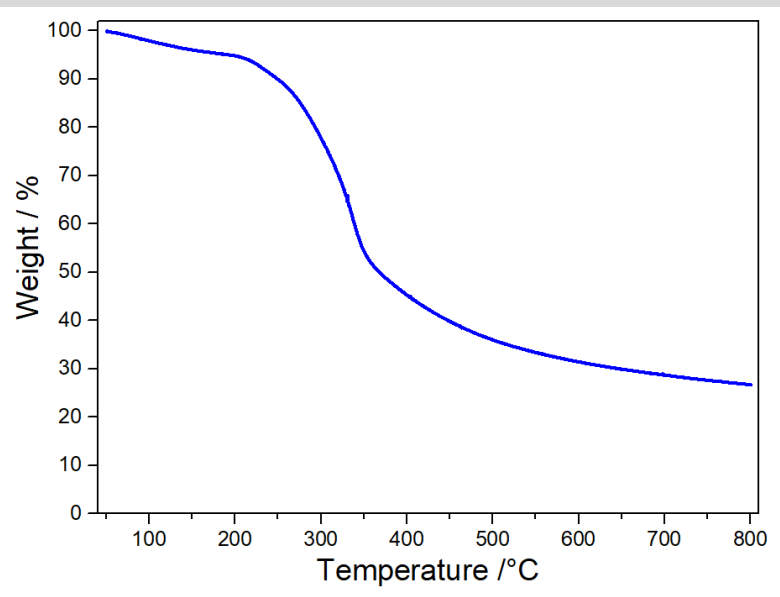

Fig. 3 Thermo gravimetric analysis (TGA) of washed pinecones.

During the carbonization step, the carbon was doped with nitrogen. According to the literature, this procedure enhances the electrocatalytic-activity of the carbon by transforming the charge density and spin density of the carbon atoms. ${ }^{74-78}$ In addition, transition metals such as $\mathrm{Co}, \mathrm{Ni}$ and $\mathrm{Cu}$, showed 
synergistic effect with the $\mathrm{N}$-doped carbon for both the ORR and OER. ${ }^{79}, 80$ The doping with nitrogen was performed using lowtoxicity and cheap urea. ${ }^{81}$ Remarkably, urea can be also derived from waste, making it a promising $\mathrm{N}$-source in the circular economy, in good accordance with the scope of the work to make environmentally friendly electrocatalysts. ${ }^{82}$ Sequentially, according to Chatha et al., ${ }^{57}$ the so-produced carbon was activated through a $\mathrm{KOH}$ washing, in order to further increase its metal adsorption properties. ${ }^{67}$ After the adsorption of the metals, polyphenols were finally added aiming at chelating and stabilizing the cobalt ions over the carbon structure. ${ }^{83-85}$

\section{Materials characterization}

As shown in SEM images in Fig. 4, prior to the activation and to the adsorption of the metals and polyphenols, the carbonized pinecones exhibited pores in the micrometer range (i.e. around $20 \mu \mathrm{m}$ in diameter).

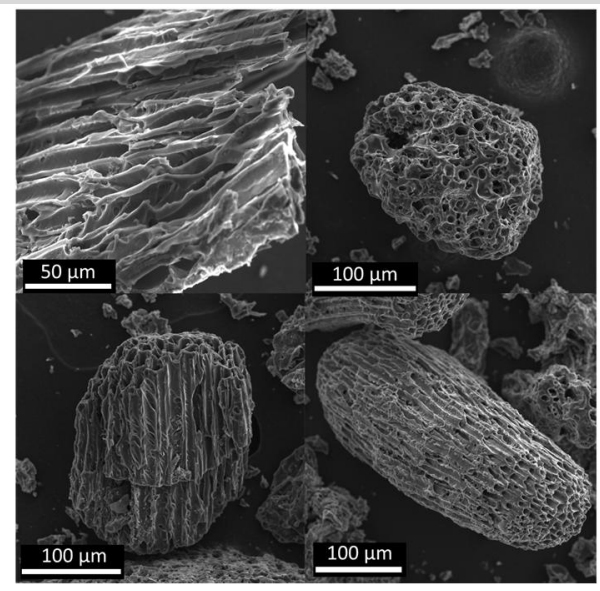

Fig. 4 SEM images of carbonized pinecones.

However, during the sequential steps of chemical activation, adsorption of metals and stabilization with polyphenols, the structure partially collapsed, as illustrated in the SEM images of the final samples, in Fig.5.

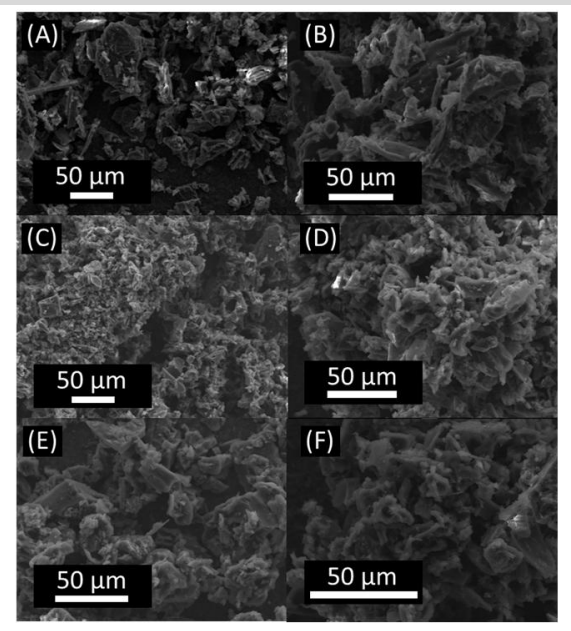

Fig. 5 SEM images of samples made from pinecones carbon. (A) Co/PC; (B) Co/N-PC; (C) Co/N-PC-pp-C; (D) Co/N-PC-pp-M; (E) Co/N-PC-pp-U and (F) Co/N-PC-pp-MU.
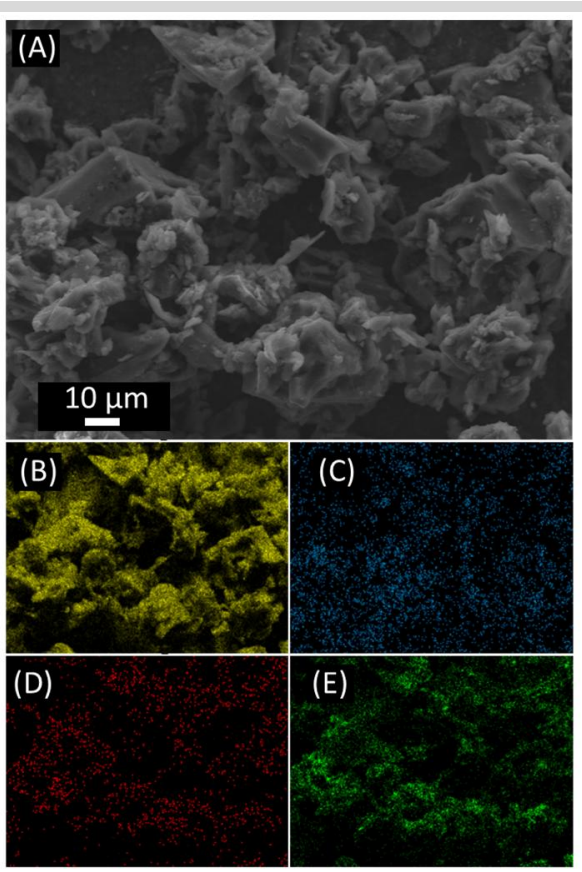

Fig. 6 SEM-EDX images with mapping analysis of (A) Co/N-PC-pp-U carbon hybrid structure: (B) carbon; (C) cobalt; (D) nitrogen and (E) oxygen.

EDX-mapping micrographs allowed the examination of the surface distribution of Co, C, O and N. Remarkably, all the samples showed a homogeneous distribution of cobalt. Fig. 6 presents the $\mathrm{C}, \mathrm{Co}, \mathrm{N}$ and $\mathrm{O}$ EDX-mapping of $\mathrm{Co} / \mathrm{N}-\mathrm{PC}-\mathrm{pp}-\mathrm{U}$, the most active sample in the tests for the OER (the EDX-mapping of all the samples can be found in the ESI Fig. S2-S4).

The phase purity and crystallinity of the synthesized samples were subsequently investigated by XRD analysis. However, due to the low crystallinity of Co as well as the low content of the metal, no relevant peak could be observed. The samples generally showed the amorphous carbon structure as indicated by the wide peak ranging from $2 \theta$ of $\sim 10^{\circ}$ to $30^{\circ}$ in their XRD diffraction patterns (see in Fig. S5 XRD patterns)..$^{86}$

The nitrogen physisorption was carried out in order to determine the specific surface areas and the pores volumes (micro and meso) of the composite materials, as reported in Table 2 (see Fig. S6 in ESI for the isotherms). Nevertheless, no significant correlation between surface areas and catalytic activities were observed.

Table 2 Surface areas and pores volumes of the samples.

\begin{tabular}{ccc}
\hline Sample & SSA m $\mathrm{g}^{-1}$ & Pores $\mathrm{cm}^{3} \mathrm{~g}^{-1}$ (micro; meso) \\
\hline Co/CC & 1493 & $0.20 ; 0.54$ \\
Co/PC & 456 & $0.12 ; 0.04$ \\
Co/N-PC & 272 & $0.03 ; 0.09$ \\
Co/N-PC-pp-C & 298 & $0.08 ; 0.03$ \\
Co/N-PC-pp-M & $<60$ & $\dot{¿} ? / \dot{¿} ?$ \\
Co/N-PC-pp-U & 147 & $0.01 ; 0.08$ \\
Co/N-PC-pp-MU & 147 & $0.02 ; 0.07$ \\
\hline
\end{tabular}

The metal loading of the samples was investigated through ICP-MS analysis. According to the results reported in Table 3 (column "Co $/ \%_{\mathrm{wt}}$ "), the average cobalt loading was found to be 
$\sim 3.4 \%$, with a standard deviation of $\sim 0.4$. Remarkably, as explained in the electrocatalytic tests, a (slightly) higher metal loading didn't directly imply a higher activity.

Table 3 Cobalt content $\%_{w t}$, determined by ICP-MS and XPS analysis (atomic concentration \%) of the metal loading on the samples.

\begin{tabular}{|c|c|c|c|c|c|c|}
\hline Sample & Co $/ \%_{w t}$ & C & 0 & $\mathrm{~N}$ & K & Co \\
\hline $\mathrm{Co} / \mathrm{CC}$ & 3.72 & 65.85 & 23.93 & 0.55 & & 6.41 \\
\hline $\mathrm{Co} / \mathrm{PC}$ & 3.92 & 45.22 & 40.29 & 0.37 & 1.22 & 12.90 \\
\hline $\mathrm{Co} / \mathrm{N}-\mathrm{PC}$ & 2.93 & 43.62 & 40.82 & 0.98 & 1.26 & 13.32 \\
\hline Co/N-PC-pp-C & 2.94 & 59.01 & 32.96 & 0.68 & 1.47 & 5.88 \\
\hline Co/N-PC-pp-M & 3.54 & 63.46 & 29.21 & 1.23 & 0.69 & 5.41 \\
\hline Co/N-PC-pp-U & 3.51 & 62.68 & 30.37 & 1.19 & 0.26 & 5.50 \\
\hline Co/N-PC-pp-MU & 3.58 & 56.64 & 32.19 & 1.04 & 2.84 & 7.29 \\
\hline
\end{tabular}

XPS measurements were performed in order to examine and study the chemical composition of the external surface of the solids as well as the chemical state of their different elements. More in details, XPS analysis allowed the evaluation of the surface chemical composition (atomic concentration \%) of $\mathrm{C}, \mathrm{O}$, $\mathrm{N}, \mathrm{K}$ and $\mathrm{Co}$.

As reported in Table 3, $\mathrm{K}$ was not found in sample $\mathrm{Co} / \mathrm{CC}$, whereas $\mathrm{P}$ $(3.26 \%)$ was observed in the form of phosphate (P $2 p$ at $134.1 \mathrm{eV}) .{ }^{87}$ On the contrary, $\mathrm{K}$ derived from the addition of $\mathrm{KOH}$ was found in all the other samples, despite the intense sequential washing procedure, being Co/N-PC-pp-U and Co/N-PC-pp-MU samples with


Fig. 7 (A) Co $2 p$ core level spectra for samples Co/CC, Co/PC, Co/N-PC and Co/N-PC-pp-C; (B) Co $2 p$ core level spectra for samples Co/N-PC-pp-U, Co/N-PCpp-M and Co/N-PC-pp-MU.

Table 4 Binding energy values, in eV, of the different constituent elements and percentages of each deconvoluted contribution, in brackets, of the studied samples.

\begin{tabular}{|c|c|c|c|c|c|}
\hline Sample & C 1s & $01 s$ & $\mathrm{~N} 1 \mathrm{~s}$ & Co $2 p_{3 / 2}$ & $\mathrm{~K} 2 p_{3 / 2}$ \\
\hline \multirow{4}{*}{$\mathrm{Co} / \mathrm{CC}$} & $284.8(76)$ & \multirow{4}{*}{532.7} & \multirow{4}{*}{400.0} & \multirow{4}{*}{781.8} & \\
\hline & $286.4(16)$ & & & & \\
\hline & $287.7(5)$ & & & & \\
\hline & $289.2(3)$ & & & & \\
\hline \multirow{4}{*}{$\mathrm{Co} / \mathrm{PC}$} & $284.8(64)$ & & \multirow{4}{*}{400.2} & \multirow{4}{*}{781.7} & \multirow{4}{*}{293.4} \\
\hline & $286.0(18)$ & $532.1(92)$ & & & \\
\hline & $288.6(4)$ & $533.6(8)$ & & & \\
\hline & 289.9 (14) & & & & \\
\hline \multirow{3}{*}{$\mathrm{Co} / \mathrm{N}-\mathrm{PC}$} & $284.8(57)$ & $5321(89)$ & \multirow{3}{*}{399.5} & \multirow{3}{*}{781.9} & \multirow{3}{*}{293.6} \\
\hline & $286.0(26)$ & $533.6(11)$ & & & \\
\hline & 288.5 (3) & & & & \\
\hline
\end{tabular}




$\begin{array}{lccccc} & 284.8(56) & & & & \\ \text { Co/N-PC-pp-C } & 286.4(29) & 531.9(68) & 400.0 & 781.7 & 293.5 \\ & 288.1(9) & 533.3(32) & & & \\ & 289.5(6) & & & & \\ \text { Co/N-PC-pp-M } & 288.4(59) & & & & \\ & 286.4(25) & 531.9 & 398.2(37) & 781.6 & 293.0 \\ & 288.2(9) & & 400.3(62) & & \\ \text { Co/N-PC-pp-U } & 289.5(7) & & & & \\ & 284.8(53) & & & & \\ & 286.4(30) & 532.1(63) & 398.2(38) & 781.9 & 293.5 \\ & 288.0(10) & 533.5(37) & 400.4(62) & & \\ \text { Co/N-PC-pp-MU } & 289.5(7) & & & & \\ & 284.8(53) & & & & \\ & 286.4(28) & 532.3 & 398.4(42) & 781.7 & 293.3 \\ & 287.7(119 & & & & \end{array}$
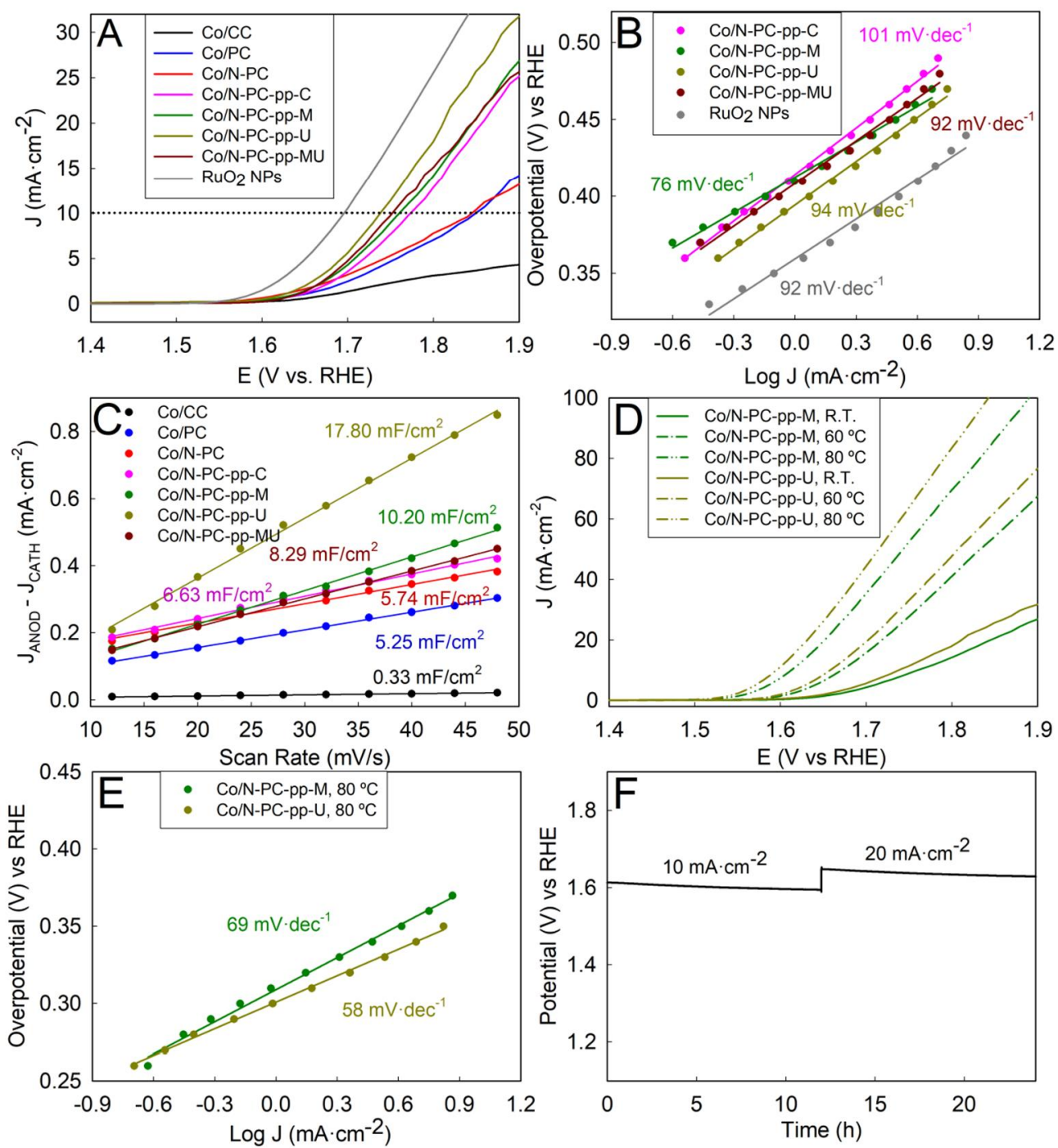

Fig.8 (A) LSV curves of GC modified with the different Co-carbon hybrid structures, and $\mathrm{RuO}_{2} \mathrm{NPs}$ as reference material; (B) Tafel polarization plot obtained from (A); (C) Plots of the difference of anodic and cathodic current densities against the scan rate for all samples; (D) Effect of the temperature increase on the LSV curves of Co/N-PC-pp-M and Co/N-PC-pp-U samples, respectively; (E) Tafel polarization plot obtained from the latter samples at $80{ }^{\circ} \mathrm{C}$; (F) Chronopotentiometric curve obtained at current densities of 10 and $20 \mathrm{~mA} \cdot \mathrm{cm}^{-2}$ for Co/N-PC-pp-U. 
Table 5. OER electrocatalytic parameters obtained from Figure 7A and 7B at room temperature.

\begin{tabular}{ccccc}
\hline & $\begin{array}{c}\text { Onset } \\
\text { potential (V) }\end{array}$ & $\begin{array}{c}\text { Overpotential }(\mathrm{mV}) \\
\text { at } 10 \mathrm{~mA} \cdot \mathrm{cm}^{-2}\end{array}$ & $\begin{array}{c}\text { Maximum current } \\
\text { density }\left(\mathrm{mA} \cdot \mathrm{cm}^{-2}\right)\end{array}$ & $\begin{array}{c}\text { Tafel slope } \\
\left(\mathrm{mV} \cdot \mathrm{dec}^{-1}\right)\end{array}$ \\
\hline BareGC & 1.70 & - & 1.0 & - \\
$\mathrm{RuO}_{2} \mathrm{NPs}$ & 1.54 & 460 & 25.5 & 92 \\
$\mathrm{Co} / \mathrm{CC}$ & 1.60 & - & 1.9 & - \\
Co/PC & 1.59 & 610 & 14.1 & - \\
Co/N-PC & 1.58 & 605 & 13.2 & - \\
Co/N-PC-pp-C & 1.57 & 540 & 25.2 & 101 \\
Co/N-PC-pp-M & 1.57 & 526 & 27.1 & 78 \\
Co/N-PC-pp-U & 1.56 & 497 & 32.0 & 94 \\
Co/N-PC-pp-MU & 1.57 & 520 & 26.3 & 92 \\
\hline
\end{tabular}

In the case of the samples obtained by treating with microwaves or ultrasound, the $\mathrm{N}$ 1s signal can be decomposed into two contributions at 398.2 and $400.4 \mathrm{eV}$, which are attributed to Pyridinic- $\mathrm{N}$ and Pyrrolic- $\mathrm{N}$, respectively. The latter results not only confirm the successful formation $\mathrm{N}$-doped active carbon species but also that pyrrolic- $\mathrm{N}$ peak is higher than pyridinic- $\mathrm{N}$ one, demonstrating that the electron pair on the pyrrolic nitrogen is involved for aromatic stabilization of cobalt ions (for the complete $C$ 1s and N 1s spectra please see ESI Fig. S7 and S8). ${ }^{89}$ Potassium, with $\mathrm{K} 2 p_{3 / 2}$ binding energy values of about $293.4 \mathrm{eV}$ was, as expected, always as $\mathrm{K}^{+} .87$

As illustrated in Fig. 7, Co $2 p$ core level spectra showed maxima at high binding energy values (781.4-781.8 eV). According to the literature, these values correspond to $\mathrm{Co}(\mathrm{II})$ species having strong interactions with oxygen. ${ }^{87}$

Co $2 p_{3 / 2}$ signals can be fitted into four contributions as observed in Figure S9 and Table S2 in ESI. The values of the maxima of these four contributions and the shape of the spectra are similar to Co(II) species such as $\mathrm{CO}(\mathrm{OH})_{2}$ and $\mathrm{CoO} .{ }^{90}$ The values of the observed doublet Co $2 p_{1 / 2}$-Co $2 p_{3 / 2}$ energy separation were in a range of 15.8 $16.2 \mathrm{eV}$, values observed for $\mathrm{CoAl}_{2} \mathrm{O}_{3}, \mathrm{Co}(\mathrm{OH})_{2} .{ }^{87}$ However, the presence of $\mathrm{Co}$ (III) species cannot be ruled out. The satellites of the Co $2 p_{3 / 2}$ signals for samples Co/PC, Co/N-PC and Co/N-PC-pp-C appeared in a range of 784.4-790.0 eV (peaks 2, 3 and 4 of Table S2), more frequent for $\mathrm{Co}(\mathrm{II})$ species. These satellites were broader for samples Co/N-PC-pp-U, Co/N-PC-pp-M and Co/N-PC-pp-MU, probably due to the enhanced coordination of Co with polyphenols.

\section{Electrochemical oxygen evolution}

OER electrocatalytic activities of the different Co-carbon samples were initially measured at room temperature. Fig. 8 displays the resulting OER polarization curves of the Co-functionalized carbonaceous materials performed in $0.5 \mathrm{M}$ $\mathrm{KOH}$ electrolyte at $2 \mathrm{mV} \cdot \mathrm{s}^{-1}$. Remarkably, the samples containing pinecones-derived carbon outperformed the electrocatalytic performances of commercially available carbons (Co/CC). As shown in Fig. 8A and Table 5 the onset potentials values at jgeo $=10 \mathrm{~mA} \mathrm{~cm}^{-2}$ were significantly lower for the catalysts composed of pinecones-derived carbon materials. These results most likely derived from the chemical activation of biomass waste with $\mathrm{KOH}$, favouring the formation of a greater number of active sites that leads to considerable improvement in electrocatalytic performance. ${ }^{91}$ Interestingly, a remarkable enhancement of the electrocatalytic response was observed after the addition of polyphenols to the nitrogen-doped carbon materials. It is attributed to the lower difference of co content between the bulk (ICP) and surface composition (XPS) of these samples (Table 3), indicating a better distribution of Cobalt ions into these Co/Carbon composites, which facilitates both the accessibility to $\mathrm{OH}$ molecules and the electronic connectivity within the whole system, shortening the ion-diffusion pathways. ${ }^{92,} 93$ More in details, the onset potential values at $\mathrm{j}_{\text {geo }}=10 \mathrm{~mA} \cdot \mathrm{cm}^{-2}$ decreased from $620 \mathrm{mV}$ to $530 \mathrm{mV}$. In this sense, the polyphenolic networks (i.e. all samples named "Co/N-PC-pp-") had a dual function into the hybrid inorganic-organic architectures: (i) the stabilization of the $\mathrm{Co}^{2+}$ cations through highly stable metalphenol complexes and (ii) the increasing of the surface density of the catalytically sites providing a enrich in $\mathrm{Co}-\mathrm{OH}$ (metal oxides) and Co-O-Co functional groups as evidenced by XPS as described above, which notably boost the catalytic activity by favouring the adsorption of OER intermediate species. ${ }^{94}$ Additionally, the hybrid organic-inorganic Co-based heterostructures were synthesized following different procedures for the adsorption of the metal (i.e. different heating methods): conventional heating, microwave-assisted heating, ultrasound heating and combined US/MW heating. The OER measurements demonstrated that the synthetic route displayed an important influence on the surface chemical composition and, therefore, on the resulting electrocatalytic properties of the samples. In fact, according to the OER curves, all the catalysts prepared through ultrasound, microwave and US/MW-assisted heating procedures (Co/N-PC-pp-U, Co/N-PCpp-MW, Co/N-PC-pp-MU) showed better electrocatalytic performances than the catalyst prepared by the conventional heating procedure (Co/N-PC-pp-C). According to the literature, ${ }^{95}, 96$ ultrasound assisted techniques can lead to a uniform and homogeneous distribution of the treated compounds (i.e. the polyphenols), sensibly enhancing the electrocatalytic activity. On the other hand, also microwave assisted techniques have been reported as efficient methods to boost the electrocatalytic activity of catalysts, due to rapid and uniform heating, which avoid the formation of thermal 
gradients (and consequent inhomogeneous particles distribution). ${ }^{97,} 98$ These thesis were enforced by the strong interaction Co-polyphenols observed in XPS.

The comparison of the activity between these "unconventionally" (MW, US and MW/US) synthesised catalysts demonstrated that sample Co/N-PC-pp-U was the most active one. Table S3 compares the OER electrocatalytic properties of the Co/N-PC-pp-U composite with other reported Co-modified materials at room temperature. In order to investigate this behaviour, the differences of anodic and cathodic current densities were plotted against the scan rates, obtaining slopes (areal capacitances) proportional to the number of active sites as well as to the electrochemical surface area of each sample (Fig. 8C). ${ }^{72,73}$ The findings demonstrated that Co/N-PC-pp-U provided the highest areal capacitance of $17.80 \mathrm{mF} \mathrm{cm}^{-2}$, which was significantly higher than those of the other samples. As a result, the compositional and structural features of the Co/ $\mathrm{N}$ PC-pp-U sample provided the highest number of active sites with the most favourable material for charge transfer reactions and electronic connectivity within the whole system. As a result, the Co/N-PC-pp-U (M) provides the better electrocatalytic performance for OER. And, according to the literature, the conventional electrochemical mechanism for OER processes in alkaline medium is called as Adsorbate Evolution Mechanism (AEM) ${ }^{99}$ which consists of 5 steps with multiple adsorbed intermediates:

(1) $\mathrm{M}+\mathrm{OH}^{-} \leftrightarrow \mathrm{M}^{-} \mathrm{OH}^{*}+\mathrm{e}^{-}$



(3) $\mathrm{M}-\mathrm{O}^{*}+\mathrm{OH}^{-} \leftrightarrow \mathrm{M}^{-} \mathrm{OOH}^{*}+\mathrm{e}^{-}$



(5) $\mathrm{M}-\mathrm{OO} * \leftrightarrow \mathrm{M}+\mathrm{O}_{2}$

Based on the study reported by Nurlaela et al.,100 OER electrocatalytic performance of the two bests samples (i.e. Co/N-PC-pp-U and Co/N-PC-pp-M), were sequentially carried out at higher temperatures (Fig. 8D). As reported in the Tafel polarization plots in Fig. 8E, a higher temperature significantly improved the OER electrocatalytic response of both samples, providing cathodic shift of the onset potential and increasing the maximum current density (please see Table S4 and S5 for the complete list of the obtained electrocatalytic parameters).
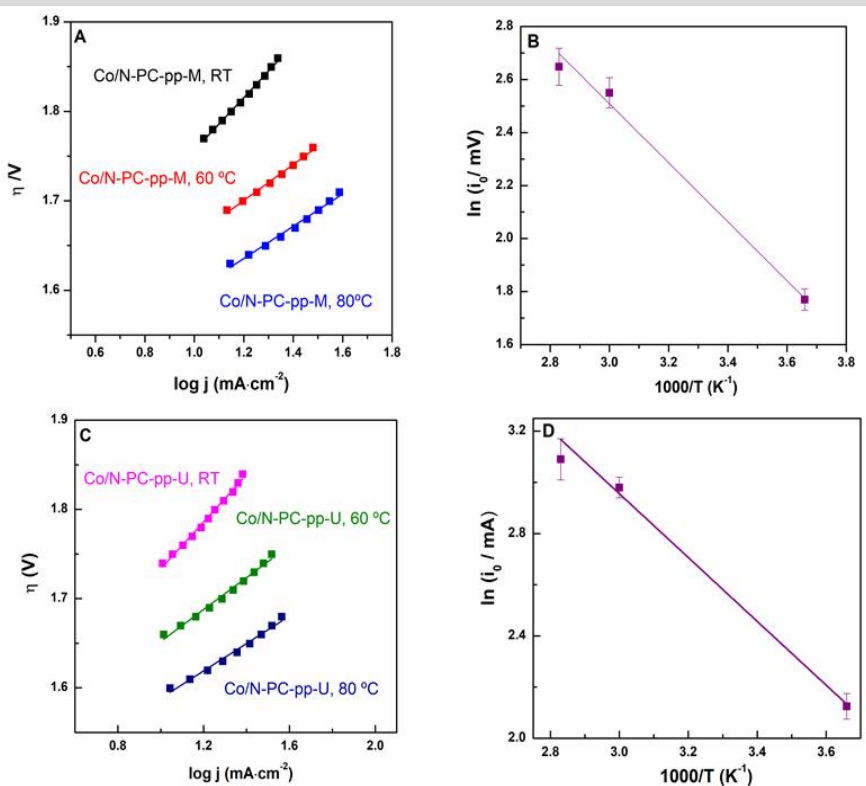

Fig. 9 Tafel plots for OER polarization curves at RT, $60^{\circ} \mathrm{C}$ and $80^{\circ} \mathrm{C}$ of $(\mathrm{A}) \mathrm{Co} / \mathrm{N}-$ $\mathrm{PC}-\mathrm{pp}-\mathrm{M}$ and (B) Co/N-PC-pp-U, respectively. Arrhenius plots of the (C) $\mathrm{Co} / \mathrm{N}$ PC-pp-M and (D) Co/N-PC-pp-U, respectively.

More in detail, Fig. 9A and $9 \mathrm{C}$ display the Tafel plots trends of the OER curves obtained for the Co/N-PC-pp-M and Co/N-PC$\mathrm{pp}-\mathrm{U}$ samples at room temperature, $60^{\circ} \mathrm{C}$ and $80{ }^{\circ} \mathrm{C}$ in $0.5 \mathrm{M}$ $\mathrm{KOH}$. Notably, the slopes of both materials slightly decrease at higher temperatures, which are related with the improvement of the OER efficiency of the samples from room temperature to $80^{\circ} \mathrm{C}$.

According to best result, sample (Co/N-PC-pp-U) can be considered as an "excellent" OER catalyst in comparison with the literature, ${ }^{66}$ requiring an overpotential of $365 \mathrm{mV}$ to deliver the current density of $10 \mathrm{~mA} \mathrm{~cm}^{-2}$, with a Tafel slope of $58 \mathrm{mV}$ $\mathrm{dec}^{-1}$. Table $\mathrm{S} 6$ compares the OER electrocatalytic properties of our best $\mathrm{Co} /$ Carbon composite with other recently reported $\mathrm{Co}$ based OER electrocatalyst materials at $80^{\circ} \mathrm{C}$. This performance was validated through durability tests performed by chronopotentiometry at current densities of 10 and $20 \mathrm{~mA} \mathrm{~cm}$ ${ }^{2}$ (Fig. 8F). ${ }^{71}$ As the potentials remained almost constant for 24 $\mathrm{h}$ at each current density, sample Co/N-PC-pp-U was demonstrated to have a good electrochemical stability and the best performance was confirmed.

Finally, using the experimental Tafel curves, the values of currents at zero-overpotentials $\mathrm{i}_{0}(\mathrm{E}=1.23 \mathrm{~V}$ vs $\mathrm{RHE})$ were obtained. The $\mathrm{i}_{0}$ values were plotted versus temperature following an Arrhenius representation (equation (i), Fig. 8B and $8 D)$, allowing the calculation of the activation energies.

$$
\left(d \ln \left(i^{0}\right)\right) /\left(d\left(T^{-1}\right)\right)=-E a / R
$$

where $\mathrm{Ea}, \mathrm{R}$ and $\mathrm{T}$ are the apparent activation energy, the typical gas constant and the temperature. The values obtained for Co/N-PC-pp-M and Co/N-PC-pp-U were $9.70 \pm 0.06 \mathrm{~kJ} \mathrm{~mol}^{-1}$ and $9.97 \pm 0.04 \mathrm{~kJ} \mathrm{~mol}^{-1}$, respectively, which are smaller than 
the activation energies of almost all the metal transition-based OER electrocatalysts reported up to now in the literature. ${ }^{100-103}$ These results strongly support the significant enhancement observed in the OER electrocatalytic behaviour at higher temperatures for the Co-synthesized electrocatalysts, which may be linked with the increasing of OER actives sites driven by some temperature-dependent structural changes at the polyphenolic networks.

\section{Conclusions}

A novel approach for the preparation of active and stable low-metal content cobalt-based carbonaceous electrocatalysts for the OER was demonstrated. Materials were prepared exploiting the metal adsorbing properties of carbon derived from pinecones, the nitrogen doping with eco-friendly urea as well as the metal chelating and stabilization characteristics of polyphenols extracted from green tea. Moreover, the approach allowed the investigation of different unconventional heating methodologies, including ultrasound, microwave and combined ultrasound-microwave techniques. The electrocatalytic tests demonstrated the co-activity and synergism of the carbon derived from pinecones, the importance of the doping with nitrogen as well as the good stabilization and enhance of activity of cobalt thanks to the presence of polyphenols. Importantly, the influence of the synthetic procedure also demonstrated that both MW and US techniques provided more active sites than conventional heating procedures, being the US one the most effective one.

\section{Conflicts of interest}

There are no conflicts to declare.

\section{Acknowledgements}

This project has received funding from the European Union's Horizon 2020 research and innovation programme under the Marie Skłodowska-Curie grant agreement No 721290. This publication reflects only the author's view, exempting the Community from any liability. Project website: http://cosmic-etn.eu/. M.C. thanks to the Andalusian Government of Spain for the UCO-1263193 project, which is financed by FEDER funds. J.J. G.-C. thanks to the Ministry of Science, Innovation and Universities of Spain (MINECO) for "Ramon y Cajal" contract (\#RyC-2014-14956), MANA (CTQ2017-83961-R) and JEANS (CTQ2017-92264-EXP) projects. E.R.C. thanks to project RTI2018-099668-BC22 of MINECO and FEDER funds. The publication has been prepared with support from RUDN University program 5100.

\section{Notes and references}

R. Cao, J. S. Lee, M. L. Liu and J. Cho, Advanced Energy Materials, 2012, 2, 816-829.
J. W. F. To, J. W. D. Ng, S. Siahrostami, A. L. Koh, Y. J. Lee, Z. H. Chen, K. D. Fong, S. C. Chen, J. J. He, W. G. Bae, J. Wilcox, H. Y. Jeong, K. Kim, F. Studt, J. K. Norskov, T. F. Jaramillo and Z. N. Bao, Nano Research, 2017, 10, 1163-1177.

3. Y. M. Li, Y. X. Lu, C. L. Zhao, Y. S. Hu, M. M. Titirici, H. Li, X. J. Huang and L. Q. Chen, Energy Storage Materials, 2017, 7, 130-151.

4. P. Albertus, S. Babinec, S. Litzelman and A. Newman, Nature Energy, 2018, 3, 16-21.

5. C. M. Cova, A. Zuliani, A. R. P. Santiago, A. Caballero, M. J. Munoz-Batista and R. Luque, Journal of Materials Chemistry A, 2018, 6, 21516-21523.

6. L. Hui, Y. R. Xue, H. D. Yu, Y. X. Liu, Y. Fang, C. Y. Xing, B. L. Huang and Y. L. Li, Journal of the American Chemical Society, 2019, 141, 10677-10683.

7. S. U. M. Khan, M. Al-Shahry and W. B. Ingler, Science, 2002, 297, 2243-2245.

8. A. Kudo and Y. Miseki, Chemical Society Reviews, 2009, 38, 253-278.

9. Q. R. Shi, C. Z. Zhu, D. Du and Y. H. Lin, Chemical Society Reviews, 2019, 48, 3181-3192.

10. H. M. Xu, S. Q. Ci, Y. C. Ding, G. X. Wang and Z. H. Wen, Journal of Materials Chemistry A, 2019, 7, 8006-8029.

11. N. T. Suen, S. F. Hung, Q. Quan, N. Zhang, Y. J. Xu and H. M. Chen, Chemical Society Reviews, 2017, 46, 337-365.

12. R. E. Fuentes, J. Farell and J. W. Weidner, Electrochemical and Solid State Letters, 2011, 14, E5-E7.

13. T. Reier, M. Oezaslan and P. Strasser, Acs Catalysis, 2012, 2, 1765-1772.

14. Y. S. Jeong, J.-B. Park, H.-G. Jung, J. Kirn, X. Luo, J. Lu, L. Curtiss, K. Amine, Y.-K. Sun, B. Scrosati and Y. J. Lee, Nano Letters, 2015, 15, 4261-4268.

15. X. X. Zou and Y. Zhang, Chemical Society Reviews, 2015, 44, 5148-5180.

16. A. L. Li, Y. M. Sun, T. T. Yao and H. X. Han, Chemistry-a European Journal, 2018, 24, 18334-18355.

17. M.-I. Jamesh and X. Sun, Journal of Power Sources, 2018 , 400, 31-68.

18. Data taken from London Metal Exchange (LME), https://www.Ime.com.

19. V. Y. Shafirovich, N. K. Khannanov and V. V. Strelets, Nouveau Journal De Chimie-New Journal of Chemistry, 1980, 4, 81-84.

20. J. H. Wang, W. Cui, Q. Liu, Z. C. Xing, A. M. Asiri and X. P. Sun, Advanced Materials, 2016, 28, 215-230.

21. J. Deng, M. M. Li and Y. Wang, Green Chemistry, 2016, 18 4824-4854.

22. H. Wu, J. Geng, H. T. Ge, Z. Y. Guo, Y. G. Wang and G. F. Zheng, Advanced Energy Materials, 2016, 6.

23. G. H. Wang, Y. J. Deng, J. N. Yu, L. Zheng, L. Du, H. Y. Song and S. J. Liao, Acs Applied Materials \& Interfaces, 2017, 9, 32168-32178.

24. X. Y. Wu, S. M. Li, B. Wang, J. H. Liu and M. Yu, Microporous and Mesoporous Materials, 2017, 240, 216-226.

25. C. Sathiskumar, S. Ramakrishnan, M. Vinothkannan, S. Karthikeyan, D. J. Yoo and A. Rhan Kim, Nanomaterials (Basel, Switzerland), 2019, 10.

26. F. Jaouen, E. Proietti, M. Lefevre, R. Chenitz, J. P. Dodelet, G. Wu, H. T. Chung, C. M. Johnston and P. Zelenay, Energy \& Environmental Science, 2011, 4, 114-130.

$27 . \quad$ Z. Y. Lin, M. K. Song, Y. Ding, Y. Liu, M. L. Liu and C. P. Wong, Physical Chemistry Chemical Physics, 2012, 14, 3381-3387. 
28.

R. J. Liu, H. B. Liu, Y. L. Li, Y. P. Yi, X. K. Shang, S. S. Zhang, X L. Yu, S. J. Zhang, H. B. Cao and G. J. Zhang, Nanoscale, 2014, 6, 11336-11343.

29. G. L. Tian, Q. Zhang, B. S. Zhang, Y. G. Jin, J. Q. Huang, D. S Su and F. Wei, Advanced Functional Materials, 2014, 24, 5956-5961.

30. J. T. Zhang, Z. H. Zhao, Z. H. Xia and L. M. Dai, Nature Nanotechnology, 2015, 10, 444-452.

31. L. M. Dai, Y. H. Xue, L. T. Qu, H. J. Choi and J. B. Baek, Chemical Reviews, 2015, 115, 4823-4892.

32. Y. Wang, Y. Nie, W. Ding, S. G. Chen, K. Xiong, X. Q. Qi, Y. Zhang, J. Wang and Z. D. Wei, Chemical Communications, 2015, 51, 8942-8945.

33. C. B. L. Nkulu, L. Casas, V. Haufroid, T. De Putter, N. D. Saenen, T. Kayembe-Kitenge, P. M. Obadia, D. K. W. Mukoma, J. M. L. llunga, T. S. Nawrot, O. L. Numbi, E. Smolders and B. Nemery, Nature Sustainability, 2018, 1, 495-504.

34. B. Zeuner, Frontiers in Energy Research, 2018, 6.

35. J. Conca, Blood batteries - Cobalt and the Congo, https://www.forbes.com/sites/jamesconca/2018/09/26/b lood-batteries-cobalt-and-the-congo/\#50208a91cc6e).

36. S. E. Skrabalak, Physical Chemistry Chemical Physics, 2009, 11, 4930-4942.

37. A. M. Schwenke, S. Hoeppener and U. S. Schubert, Advanced Materials, 2015, 27, 4113-4141.

38. M. J. Huelsey, C. W. Lim and N. Yan, Chemical Science, 2020, 11, 1456-1468.

39. J. A. Menendez, A. Arenillas, B. Fidalgo, Y. Fernandez, L. Zubizarreta, E. G. Calvo and J. M. Bermudez, Fuel Processing Technology, 2010, 91, 1-8.

40. A. Zuliani, A. M. Balu and R. Luque, Acs Sustainable Chemistry \& Engineering, 2017, 5, 11584-11587.

41. A. Zuliani, M. J. Munoz-Batista and R. Luque, Green Chemistry, 2018.

42. C. M. Cova, A. Zuliani, M. J. Munoz-Batista and R. Luque, Acs Sustainable Chemistry \& Engineering, 2019, 7, 13001307.

43. A. Zuliani, P. Ranjan, R. Luque and E. V. Van der Eycken, Acs Sustainable Chemistry \& Engineering, 2019, 7, 5568-5575.

44. K. Martina, F. Calsolaro, A. Zuliani, G. Berlier, F. ChavezRivas, M. J. Moran, R. Luque and G. Cravotto, Molecules, 2019, 24

45.

H. Jin, J. Wang, D. Su, Z. Wei, Z. Pang and Y. Wang, Journal of the American Chemical Society, 2015, 137, 2688-2694.

46. A. Aijaz, J. Masa, C. Roesler, W. Xia, P. Weide, A. J. R. Botz, R. A. Fischer, W. Schuhmann and M. Muhler, Angewandte Chemie-International Edition, 2016, 55, 4087-4091.

47. X. T. Yuan, H. X. Ge, X. Wang, C. L. Dong, W. J. Dong, M. S. Riaz, Z. W. Xu, J. X. Zhang and F. Q. Huang, Acs Energy Letters, 2017, 2, 1208-1213.

48. J. J. Zhao, X. Quan, S. Chen, Y. M. Liu and H. T. Yu, Acs Applied Materials \& Interfaces, 2017, 9, 28685-28694.

49. M. E. Argun, S. Dursun, K. Gur, C. Ozdemir, M. Karatas and S. Dogan, Cellulose Chemistry and Technology, 2005, 39, 581-591.

50. M. E. Argun, S. Dursun, K. Gur, C. Ozdemir, M. Karatas and S. Dogan, Environmental Technology, 2005, 26, 479-487.

51 M. E. Argun, S. Dursun, M. Karatas and M. Guru, Bioresource Technology, 2008, 99, 8691-8698.

52. S. Shrestha and W. E. Mustain, Polymer Electrolyte Fuel Cells 10, Pts 1 and 2, 2010, 33, 293-302.
53. U. Gecgel, K. Sezer and H. Kolancilar, Asian Journal of Chemistry, 2010, 22, 3936-3942.

54. A. E. Ofomaja and E. B. Naidoo, Journal of the Taiwan Institute of Chemical Engineers, 2011, 42, 480-485.

G. Degirmen, M. Kilic, O. Cepeliogullar and A. E. Putun, Water Science and Technology, 2012, 66, 564-572.

56. F. Deniz, Desalination and Water Treatment, 2013, 51, 4573-4581.

M. J. Saif, K. M. Zia, R. Fazal ur, M. Usman, A. I. Hussain and S. A. S. Chatha, Water Environment Research, 2015, 87, 291-297.

58. H. S. Altundogan, A. Topdemir, M. Cakmak and N. Bahar, Journal of the Taiwan Institute of Chemical Engineers, 2016, 58, 219-225.

59. M. A. Martin-Lara, G. Blazquez, M. Calero, A. I. Almendros and A. Ronda, International Journal of Mineral Processing, 2016, 148, 72-82.

60. A. D. Igalavithana, S.-E. Lee, Y. H. Lee, D. C. W. Tsang, J. Rinklebe, E. E. Kwon and Y. S. Ok, Chemosphere, 2017, 174, 593-603.

61. H. Wang, Z. Xin and Y. H. Li, Topics in Current Chemistry, 2017, 375.

62.

B. Wurster, D. Grumelli, D. Hoetger, R. Gutzler and K. Kern, Journal of the American Chemical Society, 2016, 138, 36233626.

63. H.-T. Shi, X.-X. Li, F.-H. Wu and W.-B. Yu, Dalton Transactions, 2017, 46, 16321-16326.

64. M. M. Najafpour and H. Feizi, Catalysis Science \& Technology, 2018, 8, 1840-1848.

65. J. Du, G. Liu, F. Li, Y. Zhu and L. Sun, Advanced Science, 2019, 6.

66. M. Tahir, L. Pan, F. Idrees, X. Zhang, L. Wang, J.-J. Zou and Z. L. Wang, Nano Energy, 2017, 37, 136-157.

67. J. Wang and S. Kaskel, Journal of Materials Chemistry, 2012, 22, 23710-23725.

68. C. Maria Cova, L. Boffa, M. Pistocchi, S. Giorgini, R. Luque and G. Cravotto, Molecules, 2019, 24.

69. T. P. Tsele, A. S. Adekunle, O. E. Fayemi and E. E. Ebenso, Electrochimica Acta, 2017, 243, 331-348.

70. D. Alba-Molina, A. R. Puente Santiago, J. J. Giner-Casares, M. T. Martin-Romero, L. Camacho, R. Luque and M. Cano, Journal of Physical Chemistry C, 2019, 123, 9807-9812.

71. D. Alba-Molina, A. R. Puente Santiago, J. J. Giner-Casares, E. Rodriguez-Castellon, M. T. Martin-Romero, L. Camacho, R. Luque and M. Cano, Journal of Materials Chemistry A, 2019, 7, 20425-20434.

72. M. B. Stevens, L. J. Enman, A. S. Batchellor, M. R. Cosby, A. E. Vise, C. D. M. Trang and S. W. Boettcher, Chemistry of Materials, 2017, 29, 120-140.

73. T. Kou, S. Wang, J. L. Hauser, M. Chen, S. R. J. Oliver, Y. Ye, J. Guo and Y. Li, Acs Energy Letters, 2019, 4, 622-628.

74. Y. Guo, P. Yuan, J. Zhang, H. Xia, F. Cheng, M. Zhou, J. Li, Y. Qiao, S. Mu and Q. Xu, Advanced Functional Materials, 2018, 28.

75. Y. Q. Zhu, W. M. Sun, J. Luo, W. X. Chen, T. Cao, L. R. Zheng, J. C. Dong, J. Zhang, M. L. Zhang, Y. H. Han, C. Chen, Q. Peng, D. S. Wang and Y. D. Li, Nature Communications, 2018, 9.

76. C. S. Huang, Y. J. Li, N. Wang, Y. R. Xue, Z. C. Zuo, H. B. Liu and Y. L. Li, Chemical Reviews, 2018, 118, 7744-7803.

77. L. Li, L. Song, H. Guo, W. Xia, C. Jiang, B. Gao, C. Wu, T. Wang and J. He, Nanoscale, 2019, 11, 901-907. 
78. H. Jiang, J. Gu, X. Zheng, M. Liu, X. Qiu, L. Wang, W. Li, Z. Chen, X. Ji and J. Li, Energy \& Environmental Science, 2019, 12, 322-333.

79. M. Sun, H. Liu, J. Qu and J. Li, Advanced Energy Materials, 2016, 6.

80. M. Longhi, C. Cova, E. Pargoletti, M. Coduri, S. Santangelo, S. Patane, N. Ditaranto, N. Cioffi, A. Facibeni and M. Scavini, Nanomaterials, 2018, 8.

81. Z. Lin, G. Waller, Y. Liu, M. Liu and C.-P. Wong, Advanced Energy Materials, 2012, 2, 884-888.

82. E. Antonetti, G. laquaniello, A. Salladini, L. Spadaccini, S. Perathoner and G. Centi, Chemsuschem, 2017, 10, 912920.

83. M. McDonald, I. Mila and A. Scalbert, Journal of Agricultural and Food Chemistry, 1996, 44, 599-606.

84. R. C. Hider, Z. D. Liu and H. H. Khodr, Flavonoids and Other Polyphenols, 2001, 335, 190-203.

85. K. Halake, M. Birajdar and J. Lee, Journal of Industrial and Engineering Chemistry, 2016, 35, 1-7.

86. H. Yu, L. Shang, T. Bian, R. Shi, G. I. N. Waterhouse, Y. Zhao, C. Zhou, L.-Z. Wu, C.-H. Tung and T. Zhang, Advanced Materials, 2016, 28, 5080-5086.

87. J. F. Moulder , W. F. Stickle , P. E. Sobol and K. D. Bomben, Handbook of $X$ Ray Photoelectron Spectroscopy, Ed. Jill Chastain, Perkin Elmer Corporation, Minesota, USA, 1992.

88. T. H. Lee and J. W. Rabalais, Journal of Electron Spectroscopy and Related Phenomena, 1977, 11, 123-127.

89. N. A. Travlou, D. A. Giannakoudakis, M. Algarra, A. M. Labella, E. Rodriguez-Castellon and T. J. Bandosz, Carbon, 2018, 135, 104-111.

90. M. C. Biesinger, B. P. Payne, A. P. Grosvenor, L. W. M. Lau, A. R. Gerson and R. S. C. Smart, Applied Surface Science, 2011, 257, 2717-2730.

91. International Journal of Hydrogen Energy, 2019.

92. M. A. Z. G. Sial, H. Lin and X. Wang, Nanoscale, 2018, 10, 12975-12980.

93. R. Boppella, J. Park, W. Yang, J. Tan and J. Moon, Journal, 2020, 156, 529-537.

94. X. Jia, J. Wu, K. Lu, Y. Li, X. Qiao, J. Kaelin, S. Lu, Y. Cheng, X. Wu and W. Qin, Journal of Materials Chemistry A, 2019, 7, 14302-14308.

95. Y. Y. Fang, X. Z. Li, Y. P. Hu, F. Li, X. Q. Lin, M. Tian, X. C. An, Y. Fu, J. Jin and J. T. Ma, Journal of Power Sources, 2015, 300, 285-293.

96. M. L. Huo, B. Wang, C. C. Zhang, S. P. Ding, H. T. Yuan, Z. Z. Liang, J. Qi, M. X. Chen, Y. Xu, W. Zhang, H. Q. Zheng and R. Cao, Chemistry-a European Journal, 2019, 25, 1278012788.

97. Z. J. Zhang, D. B. Zhou, J. J. Liao, X. J. Bao and S. P. Luo, Journal of Alloys and Compounds, 2019, 786, 134-138.

98. S. R. Ede, S. Anantharaj, B. Subramanian, A. Rathishkumar and S. Kundu, Energy \& Fuels, 2018, 32, 6224-6233.

99. Z.-F. Huang, J. Song, Y. Du, S. Xi, S. Dou, J. M. V. Nsanzimana, C. Wang, Z. J. Xu and X. Wang, Nature Energy, 2019, 4, 329-338.

100. E. Nurlaela, T. Shinagawa, M. Qureshi, D. S. Dhawale and K. Takanabe, Acs Catalysis, 2016, 6, 1713-1722.

101. M. H. Miles, G. Kissel, P. W. T. Lu and S. Srinivasan, Journal of the Electrochemical Society, 1976, 123, 332-336.
102.

D. M. Sayed, G. A. El-Nagar, S. Y. Sayed, B. E. El-Anadouli and M. S. El-Deab, Electrochimica Acta, 2018, 276, 176183.

103. M. Suermann, T. J. Schmidt and F. N. Buchi, Electrochimica Acta, 2018, 281, 466-471. 